\title{
Improving Junction Quality via Modifying Si Surface to Enhance Performance of PEDOT:PSS/Si Hybrid Solar Cells
}

\author{
Ting $\mathrm{Gao}^{a}$, Qi Geng ${ }^{a}$, Zhongliang $\mathrm{Gao}^{b}$, Yingfeng $\mathrm{Li}^{b}$, Lei Chen ${ }^{a}$, Meicheng $\mathrm{Li}^{b}{ }^{*}$ *
}

${ }^{a}$ School of Mathematics and Physics, North China Electric Power University, Beijing 102206, China.

${ }^{b}$ State Key Laboratory of Alternate Electrical Power System with Renewable Energy Sources, School of New Energy, North China Electric Power University, Beijing, 102206, China.

* Corresponding author information: E-mail: mcli@ncepu.edu.cn; Fax: +86 106177 2951; Tel: +86 106177 2951.

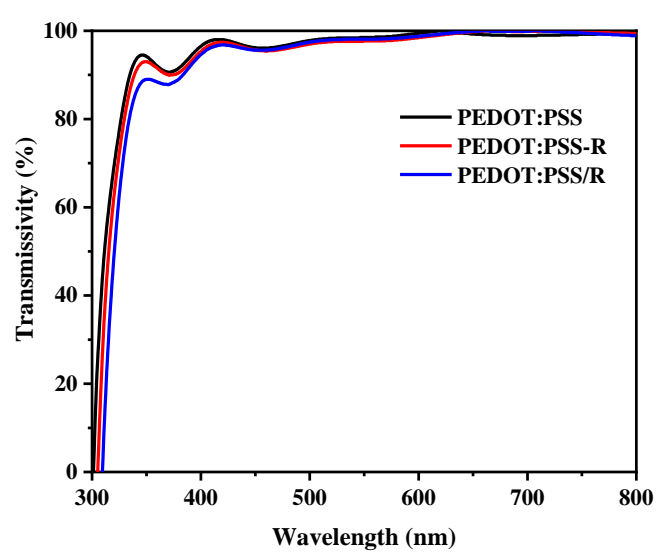

Figure S1. Transmissivity of films with PEDOT:PSS, PEDOT:PSS-R and PEDOT:PSS/R. 